\title{
Razón y pasión en Hume (sobre la miseria de la Razón demostrativa)
}

\author{
YolandA RUANO DE LA FUENTE \\ Universidad Complutense, Madrid
}

\begin{abstract}
«Echaste un velo de sombra sobre el bello mundo y vas creyendo ver, porque mides la sombra con un compás» (Antonio Machado)

«Tengo para mí que las ilusiones son algo en cierto modo real, puesto que son ingredientes esenciales del sistema de la naturaleza humana dados por la naturaleza a los hombres todos; de modo que no es lícito despreciar esas ilusiones como si fueran sueños de un individuo; sin ellas, nuestra vida sería cosa bien misérrima y bárbara» (Leopardi, Zibaldone di pensieri, I, 52)
\end{abstract}

RESUMEN. Este artículo pretende mostrar la crítica de Hume a la tradicional oposición entre razón y pasión. Frente al modelo de razón geométrica y de metafísica esencialista de cuna platónico-pitagórica, Hume apuesta por otra fuente de certezas «a la medida de lo humano», capaz de superar las «miserias» - limitaciones y excesos ideológicos- de esa razón demostrativa e intuitiva. En las cuestiones de hecho y en la moral no hay autoevidencias geométricas. Sólo un nuevo y más amplio modelo de racionalidad será válido para reflexionar sobre esas cuestiones. Junto a la razón matemática y sus certezas plenas, habría otra forma de certeza igualmente válida, pero mucho más útil, que Hume descubre arraigada en la dimensión pasional humana. Alumbra así «lo otro de la razón» en el interior de la misma, anticipando importantes ideas de autores contemporáneos críticos de la «razón carismática» moderna.

Palabras clave: Pasión, razón geométrica, creencia, modernidad, racionalismo, empirismo, dogmatismo, escepticismo, crítica de la metafísica.
Abstract. This paper attempts to review Hume's criticism of the traditional confrontation between reason and passion. Against the model of a geometrical reason, Hume suggests another possible source of certainty which is capable of overcoming the «miseries» - limits and ideological excesses - of that demonstrative and intuitive reason. There are no geometrical self-evidences in issues concerning facts and morality. Only a renewed and wider concept of rationality is valid when thinking about those issues. Besides mathematical reason and its absolute certainties, there would be another kind of equally valid, but much more useful certainty, that Hume discovers as rooted in the sentimental dimension of human beings. Thus, he reveals «the other of reason» inside reason itself, foreseeing important ideas of contemporary authors, who are critical with the excesses of the modern «charismatic reason».

Key words: Passion, geometrical reason, belief, modernity, rationalism, empiricism, dogmatism, critic of metaphysic. 


\section{Introducción: Autorreflexión crítica de la Modernidad}

Puede leerse a Hume como un destacado crítico de una particular metafísica levantada sobre el modelo de racionalidad matemático-geométrico. El optimismo ingenuo de una razón deificada, ajena a la condición humana, tanto como su carácter ideológico, serían, desde esa lectura, dos de los puntos medulares que permitirían vertebrar buena parte, si no la totalidad, del discurso humeano. Ahora bien, esa crítica de una determinada noción de «razón»-excesivamente restringida y buscadora de rigor matemático- que la modernidad impone, es emprendida desde las propias coordenadas modernas. Elabora Hume, en este sentido, una autorreflexión crítica de la Modernidad. No podía ser de otro modo en un representante paradigmático del pensamiento ilustrado. El lema ilustrado, definido a la perfección por Kant como el arrojo a hacer uso de la propia razón y a doblegarnos a su legalidad, queda, sin duda, anticipado no sólo en el espíritu, sino en la propia letra de Hume ${ }^{1}$. Así en una carta anterior a la redacción del Treatise (1734), dirigida al Dr. George Cheyne, tras confesar el interés rector de todas sus reflexiones, los asuntos morales ${ }^{2}$, indica haber descubierto el único modo adecuado de proceder en ellas: abandonar todo prejuicio tradicional y personal y centrarse en el estudio de la naturaleza humana, de cuyo conocimiento todo enunciado moral depende ${ }^{3}$.

Desde esa conciencia inaugural y autofundante, se insta a un «comenzar de nuevo» desde uno mismo. En esto Hume no parecería distinto a cualquier autor moderno, si no fuese porque él sitúa ahora ese prejuicio - que debe abandonarse- en la propia razón, en esa nueva autoridad moderna que reemplaza a la tradición; pero que al hacerlo, parece, sin embargo, conservar de ella su talante dogmático. El objeto de crítica será pues una razón reducida, entendida meramente como razón demostrativa e intuitiva, como instancia destinada a lograr certezas absolutas, esas certezas que resultan del operar con idealidades matemáticas. Una razón que falsea la condición humana, ensalza su dimensión especulativa y desatiende su dimensión activa, es ajena a las necesidades pragmáticas, a la corporalidad y a la pasión, propias del animal humano ${ }^{4}$. No es de extrañar así que el L.II del Treatise mencione explícitamente ese prejuicio, tan arraigado en toda filosofía antigua y moderna, no menos que en el sentir popular: «la eternidad, invariabilidad, origen divino de la razón» frente a «la ceguera, inconstancia y falsedad de la pasión». Mostrar el carácter falaz de esta afirmación que asegura la primacía de la razón sobre la pasión, será, en buena medida, su propósito. La razón autodivinizada será desvelada como fuente del error y sede también del fanatismo y de la intolerancia ${ }^{5}$.

Por tanto, «ese nuevo comienzo desde uno mismo» apuntaba ya a un fin prefijado: refutar la metafisica racionalista, de corte esencialista, que al tomar el modelo matemático como modelo de racionalidad, identifica reductivamente la racionalidad demostrativa e intuitiva - fuentes de certezas absolutas - con «la» racionalidad. No es sólo falso este «reduccionismo», sino también ideológico. Estar asentada en lo a-racional y ser refugio de lo irracional y, a veces, del horror, es la doble «acusación» humeana a la metafísica, esa metafísica dogmática que oficia de fundamento especulativo de la autoridad religiosa, supuestamente deslegitimada en una era secularizada como quiere ser la Ilustración.

Hume desvela, en este sentido, que el modelo de racionalidad y de subjetividad que la metafísica tradicional construye es 
un modelo falso. Y aunque como moderno e ilustrado Hume haga del sujeto la instancia fundadora del sentido, subrayará, con todo, dos cosas. De un lado, que esa instancia constituyente de sentido es algo en sí mismo constituido. De otro, que la razón misma lejos de ser soberana, autotransparente y autónoma, se nutre de una pasión. El sujeto, refiere Hume una y otra vez, llega propiamente a ser sujeto fundante y regulador, esto es, llega a ser «naturaleza» a través de la experiencia reiterada, del hábito. Descubre esto Hume tras un análisis genético de ese sujeto-naturaleza; tal análisis le permite concluir que finalmente el mecanismo que activa y constituye al sujeto como instancia legisladora, como «naturaleza», ocupa ese lugar tan despreciado por la tradición, ese lugar marcado con el nombre de lo «irracional». Hume no tiene más remedio que arruinar la asentada oposición entre razón y pasión. La arruina teniendo en cuenta, en primer lugar, que la tradición acuña un concepto de razón y de argumentación racional excesivamente restringido, estrecho y corto para abordar la esfera de los acontecimientos y de la acción humana. Frente a ese concepto, elabora un nuevo concepto de racionalidad más amplio y que de ningún modo lucha contra pasión alguna: la argumentación racional sobre hechos y acciones resulta de una pasión que opera al modo en que lo hacen los instintos en los animales. De este modo queda alumbrado lo «otro de la razón» en el interior de la misma razón, como su raíz última, tal y como harán después importantes autores contemporáneos conscientes de la imagen excesivamente deificada de la razón moderna.

Por otro lado, el carácter ideológico de la metafísica parecía inquietarle a Hume especialmente. Fue testigo de que el discurso racionalista muy a menudo ha devenido un puro instrumento legitima- dor de la autoridad religiosa y de sus inconfesables fines. La fama de filósofo ateo no le impidió a Hume exponer en boca de Filón su respeto por la verdadera religión como respeto sentía también por la verdadera metafísica: «Pero tan grande es mi veneración por la religión verdadera como lo es mi aborrecimiento de las supersticiones vulgares; y siento un placer especial, debo confesarlo, en llevar los principios de la superstición hacia el absurdo, y, a veces, hacia la impiedad» ${ }^{6}$. El empeño en desvelar el absurdo y hasta la impiedad en estos discursos ideológicos obedece al convencimiento de que mientras «los errores en materia de filosofía son solamente ridículos, en materia de religión son peligrosos» ${ }^{7}$. Peligrosos tanto para el propio sentimiento religioso como para la convivencia pacificada. En este sentido, Filón concluía que no otra cosa que la impiedad resultaba precisamente del intento de Cleantes de racionalizar las cuestiones de fe. Y añadiríamos, no otra cosa que las guerras de religión que asolaban Europa eran un buen ejemplo del uso ideológico de las creencias. Afortunadamente, «los hombres siempre derivaron y siempre derivarán sus sentimientos religiosos de otras fuentes» distintas de los razonamientos metafísicos ${ }^{8}$.

La denuncia de Hume, por tanto, reclamaba la separación de ciencia y creencia religiosa como medio de preservar la dignidad de cada una de ellas. Pero su lucidez fue aún mayor. Atisbó algo que haría correr ríos de tinta pasando el tiempo, a saber, que el origen último de esos peligros y de esos reales males del exceso celo racionalista estaba, en realidad, en la pretensión de la Filosofía de lograr una objetividad «deductiva» e «intuitiva» — esto es, «científica» u «objetiva». Cientificidad que, con todo, él mismo exigió para el Treatise, en cuanto proyecto de una «ciencia de la naturaleza humana fundamento de todas las demás». Él mismo podría pa- 
recer haber sucumbido a esas pretensiones fundamentadoras últimas, de no ser porque las palabras finales de aquella obra de juventud, más allá del tono escéptico que desprenden, pretenden en realidad mostrar los absurdos, delirios y vaciedad a los que desemboca una razón filosófica aferrada a los criterios de cientificidad tradicional (defendidos a la perfección por Descartes y Locke). Pero esas palabras finales no fueron bien entendidas ni en su tiempo ni después por la mayoría de sus intérpretes, que - a mi juicio - sobrevaloran el tono escéptico de esas palabras y pierden de vista su verdadero sentido. Quizá fuera esta incomprensión una de las razones por las que Hume llegó a renegar en su madurez de ese espléndido escrito de juventud. Sea como quiera, esa obra mostraría, según la hipótesis aquí barajada, el mal que afectaba al conjunto de la filosofía tradicional, y que - en un lenguaje protonietscheano- Hume describió así. Es un hecho - quizá el de la entera historia de la metafísica - que cuando la razón quiere abarcarlo todo, «nada» queda en pie. $\mathrm{O}$, de otro modo: cuando la «arrogante» razón humana cree que nada es demasiado difícil para ella, «profana los más íntimos santuarios de todo templo». Hasta el punto de que al adentrarse persiguiendo objetividad en todos los terrenos, se topa con la nada como fundamento, con el escepticismo y el fin de la reflexión filosófica.

Desplazar a la razón teórica para dejar paso a la creencia es una constante en Hume. O, mejor, asentar la misma razón teórica en el espacio de la creencia, que a su vez queda fundada en el hábito, en la experiencia reiterada y en el poder creador, poiético de la imaginación. Ésta es una novedosa idea de consecuencias nada despreciables para los afanes fundamentadores-cientificistas de la metafísica tradicional. De alguna manera Hume alumbró en este sentido - permítaseme usar estas imágenes - que la nave del racio- nalismo occidental empeñada en acotar territorios inviolables de objetividad plena, arribó a un único puerto demasiado insatisfactorio para ser el lugar de destino. Ese único lugar donde cabía lograr la certeza absoluta buscada resultó ser el ámbito de las relaciones de ideas; en él la razón podía ciertamente analizar, ordenar, deducir y extraer un conjunto de conclusiones que además de tener un campo de aplicación limitado, eran tan ajenas y extrañas a las informaciones del sentido común como inoperantes para el sujeto corriente, para ese sujeto que además de calcular, clasificar, deducir e intuir con certeza objetiva, deliberaba, actuaba, sentía y quería. Para estos últimos menesteres, Hume mostró que no son el cálculo y la deducción las adecuadas, sino otra instancia tradicionalmente despreciada por su irracionalidad: el sentimiento de creencia, formado a través del hábito con el concurso de la (denostada por arbitraria) «imaginación». En aras de la certeza plena, por tanto, el rumbo de la nave racionalista, empeñada en sus objetivos, bordeaba el delirio - filosófico, cuando no político. Ante ello, el filósofo escocés invita a tomar conciencia de que eso que la tradición ha llamado «razón» es en realidad mucho más ciega de lo que se cree, debido a su vaciedad de contenido, más inútil e insensible, por su formalidad y, por ello mismo, deviene a menudo inhumana cuando se la aplica a los asuntos práctico-morales y políticos. No parece que podamos obtener (ya) la objetividad deseada sobre estos asuntos del máximo interés que impulsaron la nave rumbo a descubrir la ciencia general siempre anhelada ${ }^{9}$.

Veamos antes de volver sobre estas ideas - que parecen anticipar ciertas intuiciones básicas de grandes críticos de los excesos del racionalismo occidental- cuál es el estatuto epistemológico de la Metafísica criticada por Hume. 
2. Génesis de la Metafísica racionalista: entre la autotrascendencia y la pura ideología

Hume inicia el Treatise y la primera Enquiry con el reconocimiento de un hecho de su tiempo (pese a ser más bien un tópico recurrente en la historia de la filosofía desde Aristóteles hasta nuestros días): el descrédito de la metafísica. Se conviene en hacerla la fuente inevitable del error y de la ausencia de certeza, a juzgar por las interminables disputas en las que se desenvuelve ${ }^{10}$. Disputas resultantes de un diálogo infructuoso - diríamos - entre el escepticismo y el dogmatismo, pues en ellas, unas veces de todo se duda, como «si todo fuera incierto», y otras se disputa con la más firme de las convicciones, «como si todo fuera cierto» - dice Hume en la Introducción del Treatise. Estériles controversias éstas, cuya aparente resolución cae del lado de la elocuencia, no de la «razón» ${ }^{11}$. El resultado de todo ello no puede ser sino la ausencia de progreso, el hecho de que la mayor parte de los problemas importantes que pueden ponerse ante el tribunal de la razón, siguen como el primer día: sumidos en la más oscura ignorancia.

¿A qué atribuir este mal de la Metafísica? Que la Metafísica se haya ganado el mayor de los descréditos se debe a que no es propiamente ciencia (properly science), no se ajusta a los requisitos epistemológicos de lo «científico». El cientificismo, la aplicación de los cánones de normatividad científica a la filosofía, es el criterio básico - como tónica de la historia de Occidente - para aceptar o rechazar la Metafísica. Y en este punto, Hume parece ser un ejemplo más de la misma voluntad de objetividad. «Principios asumidos confiadamente» (taken upon trust), sin fundamento sólido, «consecuencias defectuosamente deducidas» a partir de ellos, $\mathrm{y}$ «falta de coherencia en las partes, pero con una aparente evidencia en el todo», «esto es lo que se encuentra por doquier en los sistemas de los filósofos más eminentes»» ${ }^{12}$. No se trata entonces de que sus teorías sean falsas; es que ni siquiera puede atribuírseles el valor de verdad o falsedad. Son carentes de significado, sin más. Incumplen los requisitos mínimos de un discurso con sentido ${ }^{13}$.

Pero ¿de dónde surge ese discurso carente de sentido, esa pura retórica inconclusa? La respuesta es doble. De un lado, de la propia constitución autotrascendente de la razón, de su insoslayable querencia a escudriñar «objetos demasiado grandes», objetos que se le escapan a sus potencias, porque éstas no están hechas para ellos, «a pesar — añade Hume - de que requerirían (por su importancia) más que ningunos otros, el que nuestra mente estuviera familiarizada con ellos» ${ }^{14}$. Pero lo cierto es que «nuestro aparejo (line) es demasiado corto para sondear tan inmensos abismos» ${ }^{15}$, y que nos sentimos ante esos objetos como «forasteros en un país extraño» ${ }^{16}$. Es decir, en él todo nos resulta ininteligible, todo se nos vuelve «un problema» donde no hay tal, porque el único problema es la pura falta de adaptación en cuanto esos forasteros que somos en el extraño país de la Metafísica. El «mal» metafísico enraíza pues en el autorebasamiento de la razón de sus límites constitutivos, en el afán de una razón «vanidosa» que soslayando su condición «humana», se sume en el más infructuoso de los delirios (filosóficos) y no puede sino generar «sofistería e ilusión» (sophistry and illusion) ${ }^{17}$.

Pero el sinsentido del discurso metafísico tiene otra causa — decíamos-: la «astucia», el artificio de las supersticiones populares (the craft of popular superstitions). Ahora ya no es sólo que la metafísica caiga en el error por su deficiencia epistemológica, sino que es pura ideología 
legitimadora del dogmatismo religioso tradicional. El atuendo revelado ya como «pseudocientífico» sirve también de asilo a un desfundamentado discurso religioso que lucha por recuperar su perdido lugar como instancia legitimadora, en un mundo que pretende afianzar su secularización. Resume Hume así:

Realmente, aquí reside la objeción más plausible y justa a una parte de la metafísica: que no es propiamente una ciencia, sino que surge, bien de los esfuerzos estériles de la vanidad humana, que penetraría en cuestiones completamente inaccesibles al entendimiento, bien de la astucia de las supersticiones populares que, siendo incapaces de defenderse a sí mismas sobre adecuados fundamentos (fair grounds), levantan estas zarzas enmarañadas (intangling brambles) para cubrir y proteger su debilidad» 18 .

Repárese en dos ideas expresadas en el texto que permiten avanzar nuestro razonamiento. Se dice en él algo ya al menos apuntado: que el absurdo del discurso metafísico resulta de un abuso lingüistico. $\mathrm{O}$, mejor, que son esas «zarzas enmarañadas», la «oscuridad de las ideas y la ambigüedad de los términos» las que producen «la ilusión» de un discurso ${ }^{19}$. De ahí que Hume encare la crítica de la razón metafísica desde una particular teoría del significado. Pero además el texto delimita «una parte de la metafísica» como la carente de significado. ¿Cuál es esa específica metafísica fuente del error, allende el entendimiento, carente de significado, infructuosa y cobijo de superstición? Sirvan las palabras de Filón contra «el argumento ontológico» como respuesta:

«(...) el argumento a priori ha sido pocas veces considerado como algo muy conveniente. Ha tenido éxito entre gentes orientadas a la metafísica y acostumbradas a los razonamientos abstractos. Estas gentes, habiendo encontrado en el estudio de las matemáticas que el entendimiento llega frecuentemente a la verdad negando las apariencias y transitando por las tinieblas, han trasplantado este mismo há- bito de pensar a cuestiones en las que no debería ejercitarse» ${ }^{20}$.

La metafísica aquí sancionada es aquella que pretende fundamentar racionalmente - desde una determinada concepción de la razón, como vemos - todo orden de conocimiento y de acción: la metafísica racionalista, de cuna platónica y cartesiana. Tiene en mente Hume a los intelectualistas morales y a todo intento de justificar racionalmente la religión y la moral (Clarke o Wollaston y el mismo Locke ${ }^{21}$ ); a todos aquellos que coinciden «en afirmar que la moralidad como la verdad se discierne meramente por medio de ideas, por su yuxtaposición y comparación» ${ }^{22}$. Lamenta también Hume la construcción de una ciencia no formal, como la moral, sobre relaciones eternas e inmutables, «tan invariables como cualquier disposición acerca de la cantidad y el número». Para Hume, la razón «abandonada a sí misma», al puro operar de sus solos principios ${ }^{23}$, a su dimensión analítica y deductiva es mucho más frágil, ciega y limitada de lo que se cree, menos autárquica y más pasiva de lo que se presume. Y cuando se aleja además de la experiencia de la vida corriente, de la práctica humana, es proclive a la contradicción, al fanatismo y a la intolerancia, según ya sabemos. Pero en cualquier caso, ésta no es más que una parte de la metafísica. Hay otra: la que Hume pretende fundamentar. Un nuevo tipo de metafísica crítica y útil. Crítica de la metafísica sofística (pura retórica sin significado) e ideológica (falsa y adulterada). Y útil (y placentera) en un doble sentido. En la medida en que al «desenmascarar» el fondo ideológico de la metafísica dogmática, impulsa la ilustración a la que el propio Hume se encomienda. Y en cuanto cumple, por añadidura, una básica función vital.

La filosofía es, en efecto, insoslayable. Responde, como veremos, a una pasión, instinto o tendencia natural de la 
subjetividad humana a «autotrascenderse», entendiendo por esta autotrascendencia el impulso a ir más allá de lo inmediatamente presente a los sentidos y a preguntarnos por los principios generales explicativos de lo que acontece. Tal impulso está tan arraigado «naturalmente» en nosotros que resulta ser la base de la creencia en la regularidad de los acontecimientos, de la anticipación del porvenir y, en suma, del conocimiento del mundo y de la actuación en él. En cuanto sujetos de acción, la filosofía es pues algo imprescindible para el desenvolvimiento de la acción misma. Es una herramienta de la naturaleza animal humana dispuesta a asegurar satisfactoriamente la vida de los agentes. «Lo que llamamos filosofía - dice Hume - no es otra cosa que una operación regular y metódica de la misma especie» que se pregunta por los principios generales explicativos de la conducta y de los razonamientos (...), que «filosofar ... no es nada esencialmente diferente de razonar acerca de la vida común»(...). Y que «todo el mundo, incluso en la vida cotidiana, se ve obligado en mayor o menor medida a profesar esta filosofía» ${ }^{24}$, si por ella se entiende «la aprehensión de principios generales explicativos» ${ }^{25}$.

Abandonar, por tanto, la filosofía así entendida incapacitaría la acción y, con ella, la vida misma. Pero encontramos que si bien es verdad que la filosofía responde a esa capacidad de autotrascendencia humana, también es verdad que esa misma capacidad de autotrascendencia puede pervertirse y negar la vida misma. En este punto, Hume parece adelantar el discurso vitalista decimonónico. La razón geométrica, repetirá muchas veces, es limitada, inflexible, inerte y nada virtuosa cuando se aplica a los asuntos humanos. Justamente ello es así porque garantizar la objetividad tal y como ésta ha sido definida y reclamada por nuestra tra- dición, comporta la rigidez y vacuidad del formalismo matemático. Y aunque a esa razón geométrica se le supone al servicio de la vida - porque por ella surge y trabaja-, acaba conformando, quizá a su pesar, un mundo de idealidades matemáticas ajeno por completo a la realidad experimentada del hombre corriente, un mundo extraño que llega incluso a contradecir el sentido común, mucho menos amigo de las abstracciones formales. La solución al «mal» que aqueja a la metafísica no es, por tanto, negarla — pues sin ella nuestra vida sería sin duda bárbara y mezquina si es que finalmente pudiera ser posible la vida humana-, sino elaborar una nueva, esta vez, fundada en el conocimiento de «la verdadera condición humana». Sólo una fuerte dosis de «pereza» (indolence)» (dice en el Treatise) o de «cobardía y falta de juicio» (cowardice and folly) ${ }^{26}$, podrían conducir al escepticismo. Pues «más fácil es evitar todo examen e investigación que saber controlarnos en una inclinación tan natural (in so natural propensity)» ${ }^{27}$. Más fácil es despreciar la filosofía que ejercer su crítica y ponernos en guardia contra los «extravíos»y «desmanes» que protagoniza cuando dirige su mirada «más allá de los asuntos humanos» hacia objetos «que caen más allá de nuestras facultades» ${ }^{28}$ : cuando se empeña, en suma, en buscar absolutos. Precisemos en qué consiste esta nueva metafísica útil y humana, proyectada por Hume.

\section{La Filosofía moral: crítica $y$ fundamento de todo saber}

El giro subjetivista de la filosofía moderna tiene como principio determinante de validación ya no el orden del ser sino el orden del pensar ${ }^{29}$. Ahora bien, ¿cuál es ese orden del pensamiento? ¿No concluye Hume que ese orden del pensar, el orden de la razón y su ley está finalmente 
sustentado en un prereflexivo orden sentimental, pasional? ¿No quiebra Hume el afán cartesiano de separar radicalmente el saber, como aquello que «el lumen naturale nos muestra», respecto del creer, entendido como lo que «la naturaleza nos enseña» y resulta de un cierto impulso espontáneo? Parece evidente que así es. El filósofo escocés quiso, en efecto, mostrar que los juicios «racionales» acerca de lo que acontece descansan en un «oculto impulso», en una operación que no representa lo que Descartes despreció como «ciego impulso», pero tampoco esos juicios resultan del lumen naturale, siempre absolutamente certero. Tan empeñado estuvo Hume en invertir la tesis cartesiana acerca de este asunto, que llegó a nombrar la razón como «un poderoso y ciego instinto» ${ }^{30}$, desafiando el lenguaje del filósofo francés y desdibujando su nítida distinción entre el saber y el creer- una nítida distinción de amplia tradición filosófica $y$, digamos además, una distinción que oficia de garante de esa misma tradición con pretensiones fundamentadoras sustantivas. Incluso el desafío va tan lejos que muchas de esas pretensiones se tambalean desde la inversión consciente por parte de Hume de afirmaciones como éstas de las Meditaciones Metafísicas:

«Cuando digo que la naturaleza me lo enseña, entiendo sólo que cierto impulso espontáneo me lleva a creerlo, no que alguna luz natural me muestre que es verdadero. Pero estas dos cosas son muy diferentes; pues todo lo que la luz natural me muestra, como, por ejemplo, que de mi duda se sigue que yo soy, y cosas semejantes, no puede ser dudoso de ningún modo, porque no puede haber ninguna otra facultad en la que yo confíe tanto como esa luz, y que pueda enseñarme que esas cosas no son verdaderas; en cuanto a los impulsos naturales, tengo advertido que me han llevado a menudo a lo peor cuando se trataba de elegir lo bueno, y no veo por qué en otro asunto he de confiar más en ellos»» ${ }^{31}$.

Socavar, en cualquier caso, los «cimientos») (fundations) de la metafísica falsa y adulterada mediante el cultivo de una nueva «verdadera metafísica», científica, útil y placentera (pues «sacar la luz de la oscuridad, por trabajoso que sea, ha de ser deleitable y producir regocijo» ${ }^{32}$ ) es, recapitulando, el objetivo de Hume. La llamará «Ciencia de la naturaleza humana» o «Filosofía moral» para distinguirla de la «Filosofía natural», a la que dedicaron su tiempo autores tan admirados por él, como Francis Bacon y Newton ${ }^{33}$. Obvio es decir que se trata de un saber autoreflexivo, en el que el sujeto se hace objeto de sí mismo, cumpliendo así con el imperativo délfico asumido en la Modernidad. El animal humano es el objeto de esta nueva metafísica, si bien en su doble dimensión, teórica y práctica. Frente a visiones reduccionistas, Hume exige abordar el ser humano en su llamada vertiente teórico-racional (en cuanto ser guiado por los principios del entendimiento), pero también y sobremanera en su vertiente activa y social (en cuanto «influido en sus actos por el gusto y el sentimiento», procurando lo agradable y evitando el dolor ${ }^{34}$ ). Así entendido lo humano, en su aspecto teórico-cognitivo y en su aspecto volitivo-activo - como veremos englobante del anterior-, la «nueva ciencia-metafísica» aceptable tendría también una doble función: analítica y terapéutica, de un lado, y positiva o sistemática, de otro.

En el primer caso, esa «nueva ciencia» sería puramente crítica, una «teoría de los límites de la razón doblada de una teoría del «significado», superadora del «mal» metafísico y propedéutica de todo saber. El «único remedio universal» para liberar la filosofía de su falsa «apariencia de ciencia y sabiduría» es aplicarnos en el razonamiento preciso y riguroso (científico) sobre los poderes, facultades y operaciones del entendimiento ${ }^{35}$.

Y también en la primera Enquiry leemos: 
«el principal obstáculo para nuestro perfeccionamiento en las ciencias morales o metafísicas es la oscuridad de las ideas y la ambigüedad de los términos...; trataremos de fijar el significado preciso de estos términos y (así) podremos alcanzar mayor claridad y precisión en sus razonamientos filosóficos de lo que hasta ahora hemos podido obtener» ${ }^{36}$.

Aunando estos dos textos, la nueva metafísica se identificaría, en una de sus partes, con un análisis crítico lógico-lingüístico, destinado a detectar discursos ideológicos y a-significativos. De conseguir esta anatomía o «geografía mental» y este análisis del significado de los términos habríamos llegado ya muy lejos» ${ }^{37}$; tan lejos como llega el Libro I del Treatise y la primera Enquiry, en los que culmina la llamada «lógica», cuyo objeto son «los principios y operaciones de nuestra facultad de razonamiento y la naturaleza de nuestras ideas» ${ }^{38}$.

Pero la «nueva ciencia» pretende además ser un sistema de todas las ciencias particulares. En consonancia con el objetivo de la filosofía tradicional, persigue si no un único principio - algo en lo que Hume desconfía-, al menos, un número de principios generales de la naturaleza humana - («fuentes secretas»), que sirvan de estructura básica de toda ciencia de fundamento de toda certeza y saber ${ }^{39}$. Tales principios generales quedan desvelados al estudiar el sujeto mismo que conoce, quiere, actúa y siente. Perseguirá así los principios del entendimiento (del razonar riguroso); pero también de las pasiones, sentimientos y de la conducta social: los principios, en suma, de lo humano en su completitud. Cierto que Hume socava una forma de saber; pero justamente para cimentar en principio otra filosofía fundante. Y así otorga «prioridad epistemológica» a «la filosofía moral» 0 «ciencia de la naturaleza humana». Porque toda ciencia depende de y remite a la naturaleza humana. Tanto los saberes aparentemente alejados de lo humano como la filosofía natural, la religión natural o las matemáticas, cuanto las que se saben más cercanas porque expresamente se ocupan del hombre (de sus operaciones mentales - como la lógica-, de nuestros gustos y sentimientos - como la crítica literaria, artística y la moral-, o finalmente la política — centrada en la vida en sociedad). Tanto unas como otras - escribe Hume - nada podrán decir «con certeza antes de que nos hayamos familiarizado con la ciencia del hombre» ${ }^{40}$. Estamos ante el «sueño antropológico» de Hume, ante el giro subjetivista de la modernidad que él sabe llevar precisamente hasta sus últimas consecuencias y desvelar sus peligros, debilidades e incluso absurdos.

Sólo hay un límite para este ambicioso proyecto: el que impone la experiencia, «nueva base» (new footing) sobre la que habrá de levantarse «la nueva ciencia». Como buen empirista, aplica al ámbito de la filosofía moral el método experimental que Lord Bacon (antes que Newton) había utilizado en su filosofía natural ${ }^{41}$. Sigue así la estela de sus compatriotas Locke, Hutcheson, Shaftesbury, Mandeville y Butler ${ }^{42}$. Ajeno pues - con Bacon - toda «anticipación del entendimiento» $\mathrm{o}-\mathrm{con}$ Newton- a toda hipótesis, la experiencia será la fuente de autoridad inamovible de los principios buscados. Ir más allá de la mera descripción de esos principios, atendiendo a algo más que a sus efectos reales o a su puro funcionamiento fáctico; o, de otro modo, perseguir el origen y causa última de esos principios, ni puede ni debe ninguna ciencia si no quiere caer en la producción de quiméricos, cuando no ideológicos discursos ${ }^{43}$.

\section{La Filosofía como crítica del lenguaje: una teoría del significado}

Examinemos ahora esa esencial «parte crítica» de la Filosofía moral o «Ciencia de la naturaleza humana», mediante la 
que el apasionado y joven Hume está dispuesto a derrumbar «los castillos en el aire» levantados por la Teología y la $\mathrm{Me}$ tafísica, y a casi desalojar las bibliotecas de Occidente con la quema de todo volumen que por no dedicarse a razonamientos sobre cantidad o número o sobre cuestiones de hecho y existencia, no podían contener sino sofistería e ilusión ${ }^{44}$. Hacemos este examen no tanto para exponer la crítica humeana del lenguaje, cuanto para rastrear el alcance y el sentido de la crítica humeana a la metafísica dogmática y, con ella, al racionalismo geometrizante. Sin duda esa parte crítica de la «nueva filosofía» es un momento concreto en el conjunto de la crítica del racionalismo moderno. A través de esta crítica queremos ir hilvanando una serie de ideas que matizan la posible interpretación escéptica de Hume, (como la de Laird, por ejemplo, y en tiempos de Hume la de Thomas Reid y James Bettie), ya descolorida, por lo demás, desde un naturalismo (como el visto a partir de Kemp Smith o Mounce), y que permiten esbozar, frente a la tendencia racionalista monolítica y restrictiva, una distinta concepción de la filosofía y de la racionalidad humana más amplia, en paralelo a la amplitud del mundo y del ser humano.

La «Filosofía moral» en su dimensión crítica consiste - decíamos- en una analítica lógico-lingüística de las potencias, ámbitos, validez y límites del entendimiento, definidora de lo propiamente cognoscible y de lo expresable con sentido. Con un instrumental teórico idéntico al de Locke y Descartes, una gnoseología de ideas, hará el más «feliz de los descubrimientos»: «un criterio universal de significado» con el que discriminar la «pura palabrería sin sentido» y de pacificar el escenario de eterna controversia habitual a la metafísica ${ }^{45}$. Pero este descubrimiento descansa en el presupuesto no cuestionado, a saber, que las condiciones de posibilidad del conocer o pensar y las condiciones de posibilidad del decir con sentido son las mismas, y que, por tanto, el lenguaje no es más que un vehículo del pensamiento. Sin abandonar la inaugurada gnoseología de ideas - como decimos-, pensar o conocer para Hume consiste simplemente en tener ideas. Por su lado, el lenguaje es un mero instrumento expresión del pensamiento, y el significado de un término coincide con el pensamiento o idea que expresa. Un término carente de significado sería, según esto, un término sin pensamiento, sin idea. No otro es el caso de la metafísica criticada: un conjunto de palabras sin significado, sin pensamiento. Esta sería una de las razones de su miseria: ocuparse de problemas que en realidad no lo son, porque son pseudocuestiones emergentes de una pura confusión lingüística, de una «enmarañada jerga» (jargon) ${ }^{46}$, «disfraz» de aparente sentido; pero, en realidad, simple flatus vocis. Y ésta es, en fin, la razón (o sinrazón) que «obstaculiza el progreso de la filosofía» ${ }^{47}$ : no decir nada que pueda resolverse. Emitir una fórmula capaz de desenredar esa confusión lingüística - que nos hace creer que pensamos o conocemos cuando en realidad sólo proferimos sonidos-, será la clave metodológica de la crítica a la metafísica. Esa fórmula es el criterio de significado felizmente hallado: el principio de copia.

\section{La legalidad de la conciencia: último criterio de significado}

Importa retener aquí que el criterio de significado determina la validez de todo pensamiento y discurso; que muestra lo impensable e indecible exponiendo las condiciones del pensar y del decir con sentido. ¿En qué consiste ese criterio de significado? En la aplicación de ese primer principio general de la naturaleza hu- 
mana, nada despreciable - avisa Humepese a su aparente simplicidad: el principio de copia como Noxon lo llama, o de derivación —como prefiere García Roca. Dice así:«Todas nuestras ideas simples proceden mediata o inmediatamente de sus correspondientes impresiones» ${ }^{48}$. No son más que copias imitativas - no arquetípicas - de las impresiones ${ }^{49}$, y en ellas tienen su «causa» ${ }^{50}$. De manera que cuando «alberguemos cualquier sospecha de que un término filosófico se emplea sin ningún significado o idea (como ocurre con demasiada frecuencia), no tenemos más que preguntarnos de qué impresión se deriva esa supuesta idea, y si es imposible asignarle una, esto servirá para confirmar nuestra sospecha» ${ }^{51}$. Cierra así Hume la sec. VII de la Enquiry: «Toda idea es copia de alguna impresión o sentimiento (sentiment) precedente, y donde no podemos encontrar impresión alguna, podemos estar seguros de que no hay idea ${ }^{52}$.

No vamos a abundar en que al elaborar Hume este criterio a partir de la descripción de la legalidad del contendido de conciencia (sensaciones, pasiones, emociones, pensamientos), es el análisis psicológico el fundamento de la reflexión crítico-filosófica. Esto es un lugar común en casi todos los comentaristas desde el mismo Husserl hasta Kemp Smith, Flew o Passmore ${ }^{53}$. Lo que sí interesa repensar aquí es la complejidad del concepto de «experiencia», siendo ella el horizonte en el que una idea adquiere significado. Ahora bien, «experiencia» y «legalidad de la conciencia» parecen constituirse a través de una provechosa interacción. Porque para que la experiencia adquiera su función fundante de significación ha de contar con otros principios que no están en ella, ha de dejarse "atravesar» por los mecanismos asociativos de la naturaleza humana. Paralelamente, la «naturaleza humana» deviene tal, esto es, opera como instancia legitimadora a través del influjo de la experiencia reitera- da. El concepto de experiencia encierra, en este sentido, una extraordinaria complejidad según la cual el significado y la validez del pensamiento y del lenguaje remiten necesariamente a las leyes de la naturaleza humana.

Reparemos en que la experiencia está caracterizada por la «inmediatez» (frente a la «receptividad», en el caso de Locke, concepto éste que garantizaba el realismo). Y pensemos que las ideas son siempre derivadas, secundarias, resultantes, por contraposición a las impresiones de sensación que son originarias, no copiadas de ninguna percepción precedente. Son propiamente «inmediatas». Lo que para Hume significa «innatas» en sentido estricto ${ }^{54}$. Recordemos además que la diferencia entre impresiones $e$ ideas es la existente entre sentir y pensar, y que aquél, el sentir, precede - de acuerdo con el principio de copia-al pensar. ¿Las razones de este sentir, de esas impresiones de sensación? «Surgen en el alma de causas desconocidas», responde Hume ${ }^{55}$. Él no lanza hipótesis alguna acerca de las «causas últimas» de ese sentir. Son «perfectamente inexplicables para la razón humana» ${ }^{56}$. Resulta así que la pieza clave de la que depende todo contenido de conciencia (pasiones, pensamiento, emociones y toda actividad entre ellas) permanece cerrada en sí misma: no remite a nada externo, al menos que podamos apuntar con certeza. La inmediatez de la experiencia vuelve problemático el acceso a un mundo de cosas externas, y por lo mismo el significado de un término no depende de «objetos» de la experiencia. El significado no puede sino remitir a la legalidad de la conciencia, una legalidad que en cuanto instancia constituyente de «la naturaleza humana» ella es propiamente la fuente de todo orden y sentido. Sin legalidad, «sin esos principios - subraya Hume - que son el fundamento de todos nuestros pensa- 
mientos y acciones no podría hablarse de (naturaleza humana), si ellos desaparecieran, ella perecería y se destruiría inmediatamente» ${ }^{57}$. Que es entonces en esta legalidad que funda «naturaleza humana» donde radica el significado, parece desprenderse de lo visto. Pero aún cabe indicar que el criterio de significado no es un principio lógico, sino una conclusión extraída de la experiencia. Resulta de una inferencia causal. De la observación de la conjunción constante entre impresiones e ideas se infiere la necesaria conexión entre ellas y la prioridad epistemológica de las primeras sobre las segundas. Por tanto, el criterio de significado remite, de nuevo, al análisis de los principios asociativos de la naturaleza humana y, más concretamente, a aquello que explica la inferencia causal. Descubrir las leyes asociativas generadoras del discurso con sentido para poder de-limitar dónde radica el sin-sentido, será entonces el paso que nos toca dar ahora.

Pero antes de ver qué tipo de leyes asociativas le interesan a Hume, recordemos qué objetos componen el discurso significativo. De la disección de ámbitos y grados de conocimiento, Hume concluye la existencia de dos únicos posibles objetos de la razón, correspondientes a las dos únicas formas posibles de investigación (de ciencia y de certeza). Las «relaciones de ideas» (ámbito de las ciencias formales) y las "cuestiones de hecho» (ámbito de lo que acontece y de la acción humana). Para las «relaciones de ideas», espacio del mero operar a priori de la razón, quedaría reservada la certeza absoluta (demostrativa o intuitiva). Es sencillamente el terreno de las verdades de razón leibnizianas, de la necesidad, regido y dispuesto por el principio de no-contradicción. En él, y sólo en él, puede hablarse de knowledge (conocimiento en sentido estricto). Diferente es el caso de los acontecimientos. Estamos en el terreno de lo que puede ser de otro modo, ajeno a la necesidad geométrica y al principio de no-contradicción: a la certeza absoluta, pues. Para las cuestiones de existencia quedaría reservada otra forma de conocimiento y otra forma de racionalidad portadora de un grado de certeza también distinto: el grado de certeza (no demostrativo) que acompaña a la reflexión sobre los acontecimientos y la acción humana. Y, por tanto, el grado de certeza de la mayor parte de las especulaciones filosóficas: aquellas que no se limiten a enunciados sobre la cantidad y el número.

Haber dicho esto adelanta mucho camino en la crítica a la metafísica, pues en esta aparentemente simple delimitación, queda ya implícita la crítica al racionalismo dogmático, que pretende hallar certezas absolutas para un ámbito de objetos en el que Hume establece su imposibilidad. Sin embargo, aún no contamos con las razones de esta imposibilidad. Sólo sabemos que las cuestiones de hecho son los objetos propios de una filosofía que tiene por objeto lo que acontece (no las «relaciones de ideas»). A esto habrá que añadir la siguiente afirmación de Hume: que todo razonamiento acerca de las «cuestiones de hecho» se funda necesariamente en las inferencias causales. Toda argumentación filosófica, «con excepción de la geometría y la aritmética», tiene su fundamento en procesos inferenciales. La crítica al racionalismo dogmático es realizada así por Hume desde una crítica de los fundamentos epistemológicos de la propia reflexión filosófica interesada en los acontecimientos y en la acción humana. Sacar a la luz que toda reflexión filosófica sobre "realidades» se funda no en la razón - la cual es idónea para las idealidades matemáticas - sino en una pasión, como veremos, hará tambalearse el edificio completo de la metafísica dogmática. 


\section{El hábito como principio fundador «de» la Naturaleza humana}

Se sabe que Hume siguió a Shaftesbury, Hutcheson y Butler en sus respectivos intentos de elaborar una doctrina del «sentimiento moral» que renuncia a situar en la razón el fundamento de las distinciones morales. Pero Hume, que gusta llevar las cosas hasta el final, concluyó que también radica en el sentimiento el fundamento de nuestros juicios sobre cuestiones de hecho y existencia. Parte para ello de la tesis de que todo razonamiento acerca de cuestiones de hecho y existencia descansa en la inferencia causal, y muestra que el fundamento de dicha inferencia no está desde luego en la naturaleza de las cosas, pero tampoco en la razón ni tan siquiera en la experiencia, sino en un principio subjetivo, llámese sentimiento o gusto mental (mental Taste) del ser humano. Una crítica desfundamentadora de la idea de causalidad como la que emprende Hume exige un análisis genético de los procesos inferenciales tal y como de hecho se producen. Hay que precisar que la inferencia causal es propiamente «una relación asociativa natural» en la que la imaginación transita de una idea o percepción presente a otra que está ausente. El poder de la imaginación consiste precisamente en este «traer a escena» algo nuevo que no está, en propiamente crear nuevos espacios de realidad imprescindibles para que tanto la ciencia como la acción humana sean posibles. Por contraste, en «las relaciones asociativas filosóficas», la imaginación tiene escaso papel. Es la razón la que relaciona dos ideas que están de hecho presentes.

Pues bien, tras examinar la génesis de la inferencia, Hume concluye la imposibilidad de justificar "racionalmente» la regularidad de la naturaleza sobre la que la inferencia descansa. Tal tipo de justificación racional sólo sería posible en el caso de que el efecto estuviera contenido en la causa. Pero ello comportaría aplicar la categoría de «necesidad» demostrativa (exclusiva de las realidades matemáticas -relaciones de ideas-) al ámbito de lo existente. Algo que Hume desestima. En los razonamientos sobre hechos, sabemos ya, no rige el principio de no contradicción: cualquier efecto puede ser concebido a partir de cualquier causa. Así la necesidad de lo existente tal y como se da no parece demostrable, pues no incurrimos en contradicción lógica cuando concebimos que podría ser todo de un modo totalmente distinto a como en realidad es. Y aunque habría quien objetase que esta dificultad radica simplemente en nuestra limitación para aprehender «las cualidades últimas de los objetos», lo cierto es que no parecemos precisar de una intuición esencial (insight) o comprensión íntima de la esencia de los cuerpos ${ }^{58}$, porque de hecho realizamos inferencias causales y las realizamos con la validez suficiente que requiere la acción. En suma, en el examen de este faktum encontramos que no es la razón demostrativa la que permite conectar causa y efecto. No es ella la que funda la inferencia.

Esta negativa a justificar racionalmente la inferencia causal viene dada por el principio de atomización perceptiva (para Deleuze, primero y fundamental de los principios de la naturaleza humana que Hume ofrece), según el cual todo objeto separable es distinguible y todo objeto distinguible es también diferente ${ }^{59}$. Cierto que «si todo efecto es totalmente distinto a la causa» - dice Hume-, «la mente nunca podrá descubrir el efecto en la supuesta causa». Y en caso de que se «hallara mediante representación a priori», habría que sospechar su entera arbitrariedad 60

Desestimada la razón demostrativa como fundamento de la inferencia casual, la pregunta gira hacia la experiencia. 
Pero la experiencia es una compleja noción en Hume, como indicamos. Ella consigue su plena significación y autoridad a través de la intervención de un principio de la naturaleza humana: el hábito. La experiencia es propiamente un «resultado». Así es: para que la «experiencia» pueda ser fundamento de nuestras inferencias causales requiere de la intervención de un principio - que no podrá ser empírico, pues caeríamos en una petición de principio, ni tampoco a prio$r i$, pues quedaría desalojado del terreno de los hechos, pero que deberá tener la misma legitimidad que tiene la razón demostrativa para los filósofos y la que tiene la observación para el hombre corriente. Hume lo encuentra: es un principio «de» la «naturaleza humana universalmente dado y bien conocido por sus efectos»: la costumbre. Se trata - decíamos- de un principio capaz de convertir la experiencia en "fundamento» ${ }^{61}$. Por sí sola - repárese - la experiencia no ofrece más que sucesión y contigüidad, mera conexión constante entre causa y efecto. No la conexión necesaria que precisa la inferencia. Sólo por la costumbre, la «naturaleza humana» «saca partido de la semejanza entre objetos distintos», convierte en útil esa semejanza -dice Hume-, y nos impulsa a suponer, a creer con firmeza que «la naturaleza actúa con regularidad» y que «el futuro se conformará al pasado». Sólo entonces el orden se desencadena, se disipa el azar, la desconexión e incomprensión de los sucesos; sólo entonces es posible el proceso inferencial que afirma el mundo y sus regularidades, que permite prever $\mathrm{y}$, lo que es fundamental, promueve la acción en él.

Por simple que pueda parecer el conectar con necesidad pasado y futuro, la razón jamás podría dar este sencillo paso por sí misma. Ha de concluirse, en suma, que es la costumbre y no la razón ni la ex- periencia el fundamento de toda inferencia; sólo ella permite vincular con necesidad las percepciones en sí mismas separables y distinguibles. La inferencia causal es, por tanto, sentida y no pensa$d a$ (ni experimentada). Resulta de una determinación instintiva o de un sentimiento irrefrenable ocasionado por la costumbre; corresponde, en fin, a lo que Hume llamó, justamente, una «relación natural».

\section{Reflexión y acción: puras funciones vitales}

Merece retener que el «fundamento de nuestras conclusiones de la experiencia», aquello que le otorga «autoridad», no es proceso alguno del entendimiento, ni de la experiencia, sino del hábito: de un principio subjetivo que impulsa a la imaginación a trabar bajo firme regularidad lo que no son más que meras afecciones del espíritu, meras secuencias de percepciones inconexas. Y que al hacer esto, el hábito funda «naturaleza humana», es decir, el espíritu deviene instancia ordenadora y donadora de sentido. Tenemos pues que la naturaleza humana es, a un tiempo, principio, fundamento, con respecto a la experiencia y «principiado» o fundado con respecto al hábito; que a la vez es origen y resultado ${ }^{62}$. Dice Hume:

«La naturaleza puede producir ciertamente todo lo que pueda resultar del hábito. Es más, el hábito no es otra cosa que uno de los principios de la naturaleza, y ella deriva toda su fuerza de ese origen» 63 .

El porqué el «espíritu», el alma o la mente ha de dar ese rodeo por la experiencia para constituirse propiamente en «naturaleza humana», en instancia constituyente y legitimadora, es algo que no le compete resolver a Hume. Como buen fenomenista, sólo da respuesta al cómo el espiritu deviene «naturaleza» «huma- 
$n a »{ }^{64}$. En este sentido, para Hume el hábito sería el esquema mediador en el que van actualizándose los principios de la naturaleza humana ${ }^{65}$, la instancia que permite constituir lo que funcionará al modo en que funciona el «instinto» en los animales:

«En efecto, después de una repetición frecuente veo que cuando aparece uno de los objetos, la mente se ve determinada por costumbre a atender a su acompañante habitual, y a considerarlo bajo una luz más intensa, en virtud de su relación con el objeto primero. Es pues esta impresión o determinación la que me proporciona la idea de necesidad» ${ }^{66}$.

Fijémonos en este texto. Indica que «la idea de necesidad», como toda idea, surge de una impresión, no sensible sino de reflexión: es un sentimiento, una determinación irrefrenable a producir inferencia: a pasar de un objeto a la idea de su acompañante habitual $^{67}$. En cuanto impresión de reflexión, deberá tener su origen en una idea, la idea de conjunción constante que la observación reiterada de casos vinculados nos ofrece. Cabe afirmar que «la necesidad es algo existente en la mente, no en los objetos» ("necessity is somenthing, that exists in mind, not in objects» ${ }^{68}$ ). Es una ley del pensamiento; pero una ley que resulta, que deviene por efecto de la costumbre. Esta subjetivización de la causalidad permite a Hume decir que la eficiencia de las causas no está en las causas mismas, ni en la divinidad, ni en la concurrencia de ambos, sino que pertenece por entero a la mente. Es «en la mente donde está el poder real de las causas a la vez que su conexión y necesidad» ${ }^{69}$.

Respecto de la razón última de esta legalidad subjetiva, sobre por qué el hábito actúa como actúa, no ensaya Hume ninguna respuesta. Sólo sabemos que hay un principio y que es subjetivo: «el hábito de contraer hábitos»». Y conocemos sus efectos: determinarnos de un modo prerreflexivo ${ }^{70}$ a generar juicios de necesidad.
La razón de esta determinación nos resulta tan desconocida como la razón de la «atracción» de los planetas - dice Hume-; «... tendremos que contentarnos con él como el principio último que podemos asignar a todas nuestras conclusiones que parten de la experiencia» ${ }^{71}$. Estamos ante un principio asociativo prerreflexivo (a-racional) «de» la naturaleza humana, que no es la «razón última», pero es lo último que podemos señalar, y es - y esto es lo que importa resaltar - la verdadera «guía de la vida humana». De él depende todo razonamiento sobre cuestiones de hecho, esto es, toda reflexión sobre el mundo y sobre la acción en él. Estamos, en fin, ante la pura legalidad de la naturaleza dispuesta por ella para realizar sus propios fines: la supervivencia de la especie y la dirección de nuestra conducta en toda circunstancia y suceso de la vida humana 72 .

Reflexión y acción serían asi puras funciones vitales. Estas son las conclusiones que se extraen de lo visto hasta aquí: que aquello que damos en llamar «razón», aquello que nos impulsa a emitir juicios, a pensar y a actuar, resulta ser una inclinación natural irreflexiva. Que no «depende toda la conducción de nuestra vida» $\mathrm{y}$ toda ciencia más que de «una especie de instinto o fuerza mecánica que actúa en nosotros sin que la conozcamos» ${ }^{73}$. Y que, por tanto, la «naturaleza humana, por medio de una absoluta e incontrolable necesidad, nos ha determinado a realizar juicios exactamente igual que a respirar y a sentir» ${ }^{74}$. La voz de la razón - frente a lo pensado por el racionalismo dogmáticoha resultado ser la más débil de las guías. Es más, sin esas propensiones últimas que constituyen la naturaleza humana - avisa Hume - «nunca sabríamos ajustar medios a fines o emplear nuestros poderes naturales en la producción de cualquier efecto. Se acabaría inmediatamente toda acción, así como la mayor parte de la especulación» 75 
El privilegio de este principio «de» la naturaleza humana, la costumbre, (que genera propiamente naturaleza, esto es, fuente de legitimidad y sentido) frente a la razón, es afirmar un mundo y un sujeto «ordenados», y promover la acción. Mas la costumbre es guía de la acción justamente en cuanto produce creencia. La inferencia va, en efecto, acompañada de creencia. Al inferir no sólo concebimos el efecto a partir de la causa, sino que creemos además que tal efecto se producirá de hecho. Concebir no es pues creer. Creer es algo más: un modo más fuerte y vivaz de concebir, una suerte de sentimiento irrefrenable que provoca el asentimiento. Y si la creencia no cuenta con el alto grado de certeza propio del razonamiento demostrativo, goza de la rapidez, seguridad y eficacia de toda operación instintiva. Como tal, consiste en una fuerza oculta a la conciencia, espontánea y evidentemente sentida, no reflexionada. Este es el carácter determinante del hábito, «que donde es más fuerte, además de compensar nuestra ignorancia, incluso se oculta y parece no darse meramente, porque se da en grado sumo» ${ }^{76}$.

Si la crítica humeana a la idea de causalidad es importante —decíamos-, lo es en la medida en que permite una nueva concepción de la racionalidad superadora de la estrechez de la racionalidad geométrica moderna, de su arrogante pretensión de ser la suprema instancia legisladora de toda la vida humana. Hume redefine el concepto mismo de racionalidad, de realidad y de lo humano, lo que le permite reelaborar una nueva concepción de la «filosofía» superadora tanto del dogmatismo racionalista como del escepticismo. Veámoslo.

\section{Conclusión: Un nuevo concepto de racionalidad}

En la carta que citamos al comienzo de este trabajo, Hume anunciaba la apertura de una nueva Scene of Thought. Sin duda, de nueva «escena del pensamiento» puede hablarse si entendemos las radicales implicaciones de la idea de creencia para la filosofía. Un nuevo concepto más amplio de racionalidad, bien llamada «creencial» o «vital», hace su aparición ahora. Las inferencias causales en las que quedan fundados todos nuestros juicios de existencias son sólo posibles en virtud de una fuerza «vital» generadora de «orden», de un férreo nexo entre el pasado y el porvenir. En ese «orden» ficcionado por obra de la imaginación creemos, y porque creemos en él podemos proyectarnos en el porvenir y actuar con un alto grado de confianza y seguridad. Hume revisó así el papel que la tradición concedió a la razón, la pasión y la imaginación. Lo que habitualmente llamamos entonces razonamiento y (objetividad) tiene ahora su fundamento (junto a la sensibilidad y la memoria) en el dinamismo de la imaginación ${ }^{77}$ : en ese operar de una facultad «mágica del alma» — en cuanto racionalmente inaccesible - que se desencadena, como ya hemos apuntado, en el trato con la experiencia reiterada. Sabemos ahora que lo que normalmente llamamos razón es «un maravilloso e ininteligible instinto de nuestras almas, que nos lleva a lo largo de un cierto curso de ideas y les confiere cualidades particulares, según sus particulares situaciones y relaciones» ${ }^{78}$. La tan citada frase del Libro III del Treatise que sentencia «la razón es, y sólo debe ser, esclava de las pasiones, y no puede pretender otro oficio que el de servirlas y obedecerlas»» ${ }^{79}$, resumiría - como vemos - lo dicho hasta aquí y unificaría el sentido de su obra epistemológica y ética.

En suma, Hume perfila una nueva concepción de la razón no monolítica, sino escindida, en correspondencia con la escisión de la realidad y del hombre. La Razón geométrica, fuente de verdad y de 
certeza, de conocimiento en sentido estricto, no sería para Hume la única forma de racionalidad posible. A su lado (y superando sus «miserias»), habría otro modo de acercamiento cognitivo a este mundo, no ya de ideas, sino de acontecimientos físicos y de acciones humanas. Junto a la de certeza demostrativa - tremendamente limitada y a veces inhumana-, habría otra forma de certeza (por pruebas) a la medida del hombre y arraigada en su dimensión pasional. De un lado, entonces, la Razón matemática y sus Idealidades. De otro, la creencia y sus contingencias. Por una parte, el ser humano en cuanto puramente racional. Por otra, el ser humano en cuanto nacido para la acción.

Ante esta radical disociación, preguntamos: ¿dónde encajar la propia reflexión del Treatise? Ella no puede dejar de ser una función vital. Y en cuanto su objeto son las «cuestiones de hecho» — esto es, en su condición de «filosofía moral»o «ciencia de la naturaleza humana»-resulta ser mera creencia sin posibilidad de justificación teórica en sentido estricto. Se comprende ahora el tono dramático del final de su Libro I del Treatise:

«después de haber realizado el más preciso y exacto de mis razonamientos, soy incapaz de dar razón alguna por la que debiera asentir a dicho razonamiento: lo único que siento es una intensa inclinación a considerar intensamente los objetos desde la perspectiva en que se me presentan» ${ }^{80}$.

No pueden justificarse racionalmente las afirmaciones de esa obra temprana. Han resultado ser simples creencias. Su legitimación sólo podrá ser pragmática, es decir, podrá ser verificada por sus resultados, por su utilidad ${ }^{81}$. Y su utilidad ¿cuál es? Creemos que, de algún modo, mostrar que la «naturaleza humana» parece también obligarnos a someter nuestras creencias (levantadas sobre los hábitos) al examen de la reflexión teórica.
Justamente a esa reflexión teórica iniciada en el Treatise, por la que el razonamiento inferencial es sometido a enjuiciamiento crítico. En este sentido, la reflexión sería una suerte de «astucia» misma de la naturaleza destinada a «curarnos» de los «desmanes» y «extravíos» que cometemos cuando cargamos el acento en una sola de sus dimensiones, ya la teórica (que nos inclina al escepticismo y acaba negando la acción y la vida), ya la práctica (que nos inclina a tomar acríticamente las creencias por la verdad). Dicho de otro modo, la nueva filosofía por la que Hume apuesta sería, en efecto, una pasión dirigida a contrarrestar el absolutismo de otras dos pasiones que igualmente nos asaltan: la voluntad de verdad $y$ de duda, y la voluntad de creer y de sentido. El equilibrio de poderes (del que hablará su contemporáneo Montesquieu), o la nivelación de ambas pasiones humanas, el pensar demostrativo y el sentir, garantizarían la vida política, la salud psíquica y social.

No debe olvidarse que Hume realiza, así lo entendemos, una doble afirmación. Nos dice que existe una «actitud natural» consistente en creer en un mundo «externo» de objetos físicos y en un mundo «interno» de objetos psíquicos. Esta inclinación a creer es fundamentalmente práctica, deriva de la necesidad humana de actuar. La práctica obliga a hacer inferencias (no estrictamente racionales) para resolver urgencias inaplazables, obliga a contraer hábitos, a tomar el pasado como regla del porvenir, siendo todo ello una consecuencia de la «irreflexividad» humana, por la que la razón no es más que «esclava de las pasiones». Pero también dice Hume que existe, al lado de esa inclinación, y en pugna con ella, otra igualmente natural a someter a crítica nuestras creencias. «Como persona que actúo - decía Hume en la 1. Enquiry - no puedo dudar de la experiencia, sólo un 
tonto o un loco lo haría. Como filósofo, ahondo en su fundamento». Pero Hume suspende la elección en favor de la especulación que nos aloja en la duda o nos lleva al absurdo de negar el mundo de objetos y hasta el propio yo, o en favor del sentido común que cree acríticamente. No puedo elegir - sentencia el Treatise - «entre una razón falsa o ninguna razón en absoluto» ${ }^{82}$. Porque la inclinación a creer es tan inextirpable como la inclinación a dudar. Y el dogmatismo que una genera es compensado con el escepticismo de la otra. La misma naturaleza se basta para curamos de nuestras creencias (irreflexivas) mediante la reflexión teórica - sin esa dimensión de racionalidad el hombre se vería conducido al fanatismo, es decir, a la confusión de sus creencias con la verdad-, y nos curamos del escepticismo, «de la melancolía y el delirio filosófico» que tal reflexión genera, mediante nuestras creencias: no podemos permanecer eternamente en la «inacción» a la que nos invita nuestra inseguridad acerca de «lo que hay» en el mundo. Tenemos que actuar lo queramos o no para preservar nuestra propia existencia, aunque, con todo, los principios que inspiran nuestras acciones sean teóricamente inconsistentes ${ }^{83}$.

Así pues, aquel lamento del final del Tratado no sería, en el fondo, sino un eficaz recurso literario destinado a introducir su nuevo concepto de filosofía crítica del dogmatismo no menos que del escepticismo. Una filosofía que pone diques a la doble pasión que nos guía: la pasión por la verdad absoluta y la pasión por la intervención activa en el mundo que se nos impone con tozudez. Una filosofía que parece ocupar justamente el lugar de la tensión-hacia-el-saber. «Tensión», porque Hume frente a las conciliaciones reduccionistas (al gusto de las justificaciones racionales de la moral y de la religión), reclama ese lugar de conflicto entre el «sentido común acrítico» y la «reflexión metafísica», entre la aceptación pasiva (por evidente) de lo dado y el escepticismo autodestructor y negador de la vida derivado de la reflexión filosófica afanada en perseguir los fundamentos hasta el final; entre las tendencias adaptativas de la parte activa de lo humano y las querencias especulativas de esa otra parte supuestamente teorético-contemplativa que mira el mundo «sub specie aeternitatis» y que, al hacerlo, pavimenta, muy a menudo, el camino del absurdo y del «delirio filosófico». En suma, entre una pasión que afirma, dice un sí acrítico a lo que se presenta, y otra que lo cuestiona desde una posición crítico-reflexiva. No es tarea de la filosofía renunciar a ninguna de ellas, sino enseñarnos a vivir en la tensión que ambas pasiones generan. Enseñarnos a vivir con nuestros pre-juicios, seguridades heredadas y pragmáticas; pero sin olvidar jamás la necesidad de examinar críticamente esas herencias y de ponernos en guarda contra la «seguridad» dogmática que, sin duda, desencadenan. Quizá sea éste el camino trazado por la filosofía humeana.

En cuanto pasión, la filosofía no podrá ser racionalmente justificada. Hume se limitará a «recomendarla» por sus efectos. Un talante ilustrado y utilitarista como el suyo la aconsejan como terapia antidogmática a la par que como inestimable fuente de placer ${ }^{84}$. Y frente a la «perezosa renuncia» a todo examen e investigación, la nueva filosofía pergeñada afronta el reto de la crítica permanente de sus naturales «extravíos», consecuencia del olvido de la especificidad de lo humano como habitante de un especial lugar intermedio, ni tan cercano a los dioses, pero tampoco alejado de los animales, al que se refiriera Aristóteles. Este lugar intermedio es apuntado por Hume en De la dignidad o miseria de la Naturaleza Huma- 
na, donde se opone a cualquier visión monista de la misma: tanto las visiones «religiosas» de la naturaleza humana proclives a la divinización y negación de las pasiones humanas (entre ellas el «egoísmo»), como las visiones que acentúan estas pasiones hasta la degradación del género humano (donde se encontrarían Mandeville o Hobbes). Ambas interpretaciones desconocen el papel de la pasión en lo humano: «Unos elevan nuestra especie hasta los cielos y presentan al hombre como un especie de semi-dios humano, que tiene su origen en los cielos y conserva trazas (marks) evidentes de su linaje y procedencia. Otros insisten en los lados oscuros de la naturaleza humana y no pueden descubrir otra cosa que una vanidad en la que supera a los otros animales, a los que tanto parece despreciar» ${ }^{85}$. Desde este lugar intermedio que disuelve la oposición radical entre razón y pasión, Hume rechaza tanto el dogmatis- mo como el escepticismo, en cuanto posturas empeñadas en soslayar la doble dimensión teórica y práctica de lo humano. Y nos sitúa en una saludable, aunque incómoda, posición de tensión entre la doble pasión que nos guía: la trascendente y la adaptativa. Porque pese a haber nacido el hombre para la adaptación feliz, para la entrega a las placenteras «ocupaciones y a los negocios», a la resolución de problemas pragmático-adaptativos y a las cuestiones de la vida común y de la experiencia cotidiana ${ }^{86}$, y pese a que «el todo constituye un intrincado problema, un enigma, un misterio inexplicable» ${ }^{87}$, sin embargo, parece que no podemos reprimir la inquietud y el placer de tornar a investigar sobre ellas. De suerte que resucitamos la pregunta por el todo una y otra vez ${ }^{88}$. Y ello a sabiendas de que la «melancolía», hija de la contradicción e incertidumbre que acompaña a la teoría, nos asaltará en cada empeño.
1 Aunque las anticipaciones de este citadísimo lema serían muy copiosas en esa época. Entre otras muchas, cabría textos de Francis Bacon, de Descartes o de Poullain de la Barre.

${ }^{2}$ Cfr. Treatise of Human Nature: being an attempt to introduce the experimental Method of experimental Method of Reasoning into Moral Subjects. L.A. Selby-Bigge. Oxford at Clarendon Press, 1888, Libro III, Parte I, sec. I, p. 455; trad. cast. de Félix Duque, Editora Nacional, Madrid, 1981, p. 672: «La moral es un asunto que nos interesa por encima de todos los demás. Así, creemos que cualquier decisión sobre este tema pone en juego la paz de la sociedad; y es evidente que esta preocupación deberá hacer que nuestras especulaciones parezcan más reales y consistentes que cuando el asunto nos resulta casi completamente indiferente». Gilles Deleuze insistió en ese interés (Empirismo et subjectivité. Essais sur la nature humaine selon Hume, París, Presses Universitaires de France, 1953. Más recientemente, ha insistido en esto John W. Danford, David Hume and the problem of reason: recovering the human sciences. New Haven/London; Yale University Press, 1990).

3 «Resolví hacer de ésta (de la naturaleza humana) mi principal objeto de estudio, y la fuente de la que derivaría toda verdad en cuestiones de Crítica (literaria y artística) así como de Moral. (....) Creo que para que un hombre tenga éxito en este estudio se requiere poco más que lo siguiente: expulsar todos los prejuicios, tanto de sus propios opiniones como de las de los demás» (The Letters of David Hume. J.Y.T. Creig edition, vol. I, pp. 13-14).

4 «Pasión» es el nombre más general en inglés para todo tipo de sentimientos. No sólo el sentimiento de placer y dolor, sino también los apetitos corporales y las emociones. Cfr. Smith, Kemp, N., The Philosophy of David Hume. A Critical Study of its Origins and Central Doctrines, London, Macmillan and co., 1949.

5 Treatise, L II, P III, sec. III, p. 413; trad. cast., p. 614: «La mayor parte de la filosofía moral, sea antigua o moderna, parece basarse en este modo de pensar; no hay tampoco campo más amplio, tanto para argumentos metafísicos como para declamaciones populares, que esta supuesta primacía de la razón sobre la pasión. La eternidad, invariabilidad y origen divino de la primera han sido presentadas para hacerla más ventajosa, mientras que se ha insistido fuertemente en la ceguera, inconstancia y falsedad de la segunda». 
Hume pondrá de manifiesto que la supuesta batalla entre razón y pasión es falsa, en la medida en que la razón que argumenta en los asuntos de la acción humana es una pasión.

6 Diálogos sobre la religión natural. Alianza, Madrid, 1999, p. 160

7 Treatise. Libro I, Parte IV, 7, 272, ed. cast. p. 425 .

8 Diálogos, p. 29

9 El problema planteado en parte de los Libros II y III es precisamente este: hacer ver que las distinciones morales no derivan de esa razón demostrativa; que, por tanto, el razonamiento demostrativo no puede ser motivo de una acción, ni evitarla, y que habrá que buscar en otro lugar que no sea la deducción racional para poder fundamentar (término que habrá también que redefinir) la acción práctico-moral. $\mathrm{O}$, de otro modo, que en cuestiones morales, no rige la autoevidencia ni el rigor matemático.

10 An Enquiry concerning Human Understanding, L.A. Selby-Bigge, Oxford, At the Clarendon Press, 1975 (2. ${ }^{\text {a }}$ ed), sec. 1, p. 11; ed. cast. de Istmo, Madrid, 2004, pp. 40-41.

11 El lenguaje de Hume es idéntico al de Francis Bacon en este punto. En Treatise. L. III, P. I, sec. I, 455 señala: «A todo razonamiento abstruso le acompaña un problema (inconvenience): puede, en efecto, hacer callar al adversario, pero no convencerle». La imputación a la escolástica de esterilidad de sus razonamientos hacían coincidir a Descartes también con Bacon, para quien igualmente tales razonamientos estaban alejados del buen sentido y eran simple fruto del ingenio y del artificio retórico. Para Hume es ahora, entre otros, John Locke quien adolece de ese problema. Resulta interesante recordar la idea del Discurso del método de que la resolución de todo problema filosófico se logra cuando la razón se impone, cuando el buen juicio, la correcta dirección del espíritu se logra. En esto, la elocuencia poco tiene que ver. La retórica es superflua porque la verdad posee para Descartes una fuerza que «subyuga al entendimiento procurando el asentimiento del adversario en la disputa, el acuerdo en materia teórica y práctica y más aún, el goce estético».

12 Treatise, p. XVII; trad. cast., p. 77.

13 Zabeeh, F., Hume, Precursor of modern Empiricism, La Haya, Martinus Nijhoff, 1970, p. 37.

14 Diálogos, p. 35.

15 Enquiry, sec. VII, P. I, 72; trad. cast. 175. He modificado la traducción. Creo que «aparejo» es más adecuado que «cuerda» para lo que aquí Hume pretende expresar

16 Diálogos, p. 35

17 Enquiry, sec. XII, P. III, p. 165; trad. cast. p. 352 .

18 Enquiry, sec. I, P. I, p. 11; trad. cast. p. $25 . \mathrm{He}$ modificado la traducción.

19 Enquiry, sec. VII, P. I, p. 61; trad. cast. p. 152 Estas palabras resonaran posteriormente en Wittgens- tein. De ahí que se haya considerado el texto de Hume como un precedente del neopositivismo en muchos sentidos. Siendo cierto esto, creo, sin embargo, que los textos de Hume anticipan además otras corrientes de pensamiento contemporáneas, críticas del excesivo celo racionalista de la filosofía tradicional (desde ideas nietzscheanas a pragmatistas). Críticas que no estando en el Tractatus, aparecen también, por cierto, en las Investigaciones filosóficas. Sobre esto, puede verse mi trabajo «La filosofía como «phármakon» del encantamiento del lenguaje», en A. Alonso y C. Galán (eds.) Wittgenstein, 50 años después. Editora Regiona de Extremadura/Gabinete de Iniciativas Transfronterizas, Mérida, 2004, vol. II, pp. 13-46

20 Diálogos, P IX, pp. 116-117.

21 John Locke, Essay, III, XI, \$16; IV, III, \$18-20. En la estela de Locke, Clarke, Wollaston y otros intentaron fundamentar la moral y la religión en la razón demostrativa. «Lo que había comenzado siendo un intento de mostrar cuántas de las cosas esenciales del Cristianismo eran demostrables con la razón, termino proclamando que sólo era esencial lo que podía ser defendido racionalmente» (Noxon, J., La evolución de la filosofia de Hume. Madrid, Revista de Occidente, 1974, p. 74). Frente a los intentos de fundar la moral y la religión en la razón, Hume señala en una carta a Hutcheson - de quien se nutre en este tema yendo más lejos que él— del 16 de marzo de 1740: «Cuando consideras que una acción o carácter es vicioso, no quieres decir más que desde la particular constitución de tu Naturaleza tienes un sentimiento (a Feeling or Sentiment) de reprobación (Blame) al contemplarlo. Vicio y virtud, por tanto, pueden compararse a los sonidos, colores, al calor y al frío, que, según la filosofía moderna, no son cualidades en los objetos sino percepciones en la mente» (Letters, pp. 39-40).

22 L. III del Treatise, P. I, sec 1, p. 457; trad. cast. p. 674

${ }^{23}$ Diálogos, p. 28. Aquí Hume parece seguir al pie de la letra a Bacon y su crítica a las «anticipaciones del entendimiento».

${ }^{4}$ Diálogos, p. 34,

25 Enquiry, sec. I, p. 15, trad. cast. p. 49

26 Enquiry, sec. I, p. 12, trad. cast., p. 41

27 Treatise, L. I, P. IV, sec. VII, p. 274, trad. cast. p. 427

${ }^{28}$ Diálogos, p. 34.

9 Hegel, Lecciones de Historia de la Filosofia, México, FCE, 1955, vol. III, p. 257.

30 Enquiry, p. 179

31 Descartes, R., Meditaciones Metafisicas, III, ed. Gredos, Madrid, 1987, pp. 34-35.

32 Enquiry, sec. I, 1, 8; p. 25; Diálogos, p. 34

33 Enquiry, sec. I, 1, p. 6; trad. cast., p. 29. La llama así para contraponerla a la filosofía natural. Sin embargo, compartirá con ella el carácter que el Oxford Dictionary atribuye al término moral: «en un amplio sentido, se aplica a toda evidencia que es meramente 
probable y no demostrativa» (Cfr. Kemp Smith, o.c. p. 99).

34 Enquiry, sec. I, 3, p. 19

35 Enquiry, sec. 1, 9, p. 27

36 Enquiry, sec. VII, 1, p. 51; 85

37 Enquiry, sec. I, 10, pp. 27-28; en p. 30 dice «anatomía».

38 Treatise, p. XIX; «An Abstract of a Book lately Published, Entituled, A Treatise of Human Nature». En ed. del Treatise de P.H. Nidditch para Oxford University Press 1978, p. 646.

39 Enquiry, sec. 1, 3, p. 12.

40 Treatise, p. XX.

41 Ha sido Passmore quizá quien ha extendido esa idea de que Hume quiso ser el Newton de las ciencias morales o sociales. Cierto que las leyes de asociación coinciden con las de gravitación universal, y que el renunciar a las causas últimas es una constante entre lo dos. Pero también es cierto que a quien Hume considera el padre de la «física experimental» es a Bacon.

$\mathrm{Y}$ así lo hace en repetidas ocasiones: Cfr. Abstract, p. 646. «Habla (refiriéndose a sí mismo Hume) con desprecio de las hipótesis, e insinúa que estos compatriotas nuestros que las han desterrado del reino de la filosofía moral han hecho un servicio aún mayor a mundo que My Lord Bacon, a quien el autor considera como padre de la física experimental».

42 Abstract, p. 646.

43 Cfr.Treatise, p. XXII; «toda hipótesis que pretenda descubrir las últimas cualidades originarias de la naturaleza humana deberá rechazarse desde el principio como presuntuosa y quimérica») (Treatise. p. XXVI).

44 Enquiry, sec. XII, P. III, 135; p. 192; trad. cast. 352. He modificado la traducción.

45 Abstract, p. 32

46 Enquiry sec. II, 22; ed. cast. p. 37. Hume profundiza la línea de análisis del lenguaje iniciada por Francis Bacon en su teoría de los idola y por Locke en la parte III de Ensayo sobre el entendimiento humano. $\mathrm{Y}$, sin embargo, a los textos de Locke dirige Hume su análisis crítico del lenguaje, por el influjo que tienen de los escolásticos, quienes «valiéndose de términos sin definir, prolongaban tediosamente sus disputas sin ni siquiera rozar el punto en cuestión. Una ambigüedad y una circunlocución semejantes me parecen presentes en todos los razonamientos de aquel gran filósofo sobre este y otros muchos asuntos» (Enquiry, sec. II, p. 24).

47 Enquiry sec. VII, p. 51; ed. cast. pp. 85-86. Filón: «A todos los hombres sensatos les disgustan las disputas verbales que tanto abundan en las investigaciones filosóficas y teológicas; y vienen a caer en la cuenta de que el único remedio a este abuso debe encontrarse haciendo definiciones claras, partiendo de las ideas precisas que deben usarse en todo razonamiento y dando a los términos que son empleados un uso estricto y uniforme». (Diálogos, p. 156).

48 Treatise, L. I, P. I, sec. I, p. 7; trad. cast., p. 94.
49 Diálogos, p. 429.

50 Treatise, L. I, P. I, p. 3; trad. cast., p. 89

51 Enquiry. sec. II, p. 22; trad. cast. p. 64

52 Enquiry, sec. VII, p. 79; trad. cast. p. 103???

53 Cfr. Husserl, E., La crisis de las ciencias europeas y la fenomenología trascendental. Barcelona Crítica, 1991 Smith, Kemp, N., o.c., Flew, Antony, Hume's Philosophy of Belief. A Study of his First Inquiry, London, Routledge \& Kegan Paul Ltd., 1961; Passmore, J., Hume's Intentions, London, Duckworth, 1968.

${ }^{54}$ Es sabido que en este punto Hume se distanció una vez más de Locke. Expone el diferente modo (y único posible) de entender el término «innato» en la famosa nota 2 de la sec. II de la 1. ${ }^{\text {a Enquiry. }}$

55 Treatise I, P. I, sec. II, p. 8, trad. cast., p. 95.

56 Treatise. L. I, P. III, sec. V, p. 85, trad. cast., p. 190. «Nunca se podrá decidir con certeza si surgen inmediatamente del objeto, si son producidas por el poder creador de la mente, o si se derivan del autor de nuestro ser»).

57 T. L. I, P. IV, sec. IV, p. 225; trad. cast., p. 366.

58 Cfr. Treatise, L. II, P. III, sec. I, p. 401; trad. cast., p. 599

59 Cfr. Treatise, L. I, P. I, sec. VII, p. 18; trad cast., p. 108.

60 Enquiry, sec. IV, p. 29; trad. cast., p. 93.

61 «Es evidente, en primer lugar, que la repetición de objetos similares en relaciones similares de sucesión y contigüidad no descubre nada nuevo en ninguno de ellos, dado que no podemos efectuar inferencia alguna a partir de esa repetición, ni hacerlo objeto de razonamientos, sean estos demostrativos o probables, como ya hemos probado» (Treatise L. I, P. III sec. XIV, p. 164; trad. cast., p. 290).

62 Cfr. Navarro Cordón, J. Manuel, «Naturaleza humana y significado (Sobre la crítica de Hume al discurso teológico)», en Revista de Filosofía, 2001: 26, pp. 85-119.

63 Treatise, L. I, P. III, sec. XVI, p. 309; trad. cast. p. 309.

${ }^{64}$ Esta pregunta así enunciada es considerada por Deleuze en la obra citada la clave hermenéutica de la reflexión humeana.

${ }^{65}$ Hume señalará las variables diferenciadoras entre individuos y grupos relativas al papel de la educación y de las costumbres, en cuanto conformadoras de opiniones predominantes. Pero más allá de ellas habría un fondo común en lo que hace a sentimientos e inclinaciones, que le permite señalar: « $i$ Se desean conocer los sentimientos, las inclinaciones y el modo de vida de los griegos y de los romanos? Estúdiese bien el temperamento y las acciones de los franceses y de los ingleses. ... Sin embargo, no debemos suponer que esta uniformidad de las acciones humanas se realiza hasta el punto de que todo hombre, en las mismas circunstancias, obrará exactamente de la misma manera, sin contar con la diversidad de caracteres, prejuicios y opiniones. En ningún ámbito de la naturaleza se en- 
cuentra uniformidad en los detalles. Por el contrario, con la observación de la diversidad de conducta en distintos hombres, podemos formar una mayor variedad de principios que, sin embargo, suponen cierto grado de uniformidad y regularidad. ¿Son distintas las costumbres de los hombres en diferentes épocas y países? Este hecho nos enseña la gran fuerza de la costumbre y de la educación que moldean la mente humana desde la infancia y le conforman un carácter fijo y establecido» (Enquiry, sec. VIII, P. I, p. 83-85; trad. cast., p. 195-99).

${ }^{66}$ Treatise, L. I, P. III, sec. XIV, p. 156, trad. cast., p. 279 .

${ }^{67}$ Treatise, L. II, P. III, sec. I, p. 400; trad. cast., p. 599.

68 Treatise, L. I, P. III, sec. XIV p. 165; trad. cast., p. 292.

69 Treatise, L. I., P. III, sec. XIV, p. 166; trad. cast., p. 293.

70 Treatise, L. I, P. III, sec VIII, p. 104; trad. cast., p. 216.

71 Enquiry, sec. V, P. I, p. 43, trad. cast., p. 119. Desde Noxon y Passmore y basándose en textos como estos, la idea de «atracción universal» de los planetas es relacionada con esta «atracción natural» de la que habla Hume, cuya razón última se nos oculta. En verdad Newton señaló: tal noción «es para mí un gran absurdo (absurdity) que creo ningún hombre que tenga competencia en materias filosóficas podrá jamás desvelar» (cit. por Kemp Smith, o.c., p. 61, n. 1)

72 Enquiry, sec V, P. II p. 55 y 56 ; trad. cast., pp. 143-45.

73 Enquiry, sec. IX, p. 109; trad. cast., p. 243.

74 Treatise, LI, P. IV, sec. I, 183, trad. cast., p. 315.

75 Enquiry, sec V, p. 45; trad. cast., 123.

76 Enquiry, sec. IV, pp. 28-29; trad. cast., p. 93 Queremos apuntar ciertas similitudes de estos textos con algunos de Nietzsche, en los que subraya también la legalidad constituyente de la imaginación, de la creencia y el hábito, y, sobre todo, su absoluta necesidad para preservar la sociedad humana. Como un simple ejemplo de la afinidad, mencionemos que en Verdad y mentira en sentido extramoral, por ejemplo, el filósofo alemán habla de un «sentimiento» o «instinto de verdad», entendido como una propensión a crear un cierto «orden» ausente en el mundo de los objetos, con vistas finalmente a preservar la vida humana en sociedad, el contrato social. Ese instinto es el responsable último de que esa actividad creadora humana de la que dependen la memoria, los sentidos y la razón -que es la imaginación - ficcione, cree metáforas útiles, en las que quedan incluidas todos los conceptos de los que se sirve la ciencia, el arte, la religión y la filosofía. Trabajamos así con cuerpos, líneas, superfi- cies, causas y efecto, identidad, cosa, yo; en ellas creemos y debemos creer, pues es esta capacidad poiética la que eleva al hombre por encima del animal. Esa creencia se nos impone de un modo prerreflexivo. Saber que la creencia funciona como funciona en nosotros, exige un análisis genético de formación de la misma. Algo que ambos autores hacen a su manera. Salvando las distancias epocales, sería interesante rastrear estas y otras similitudes.

77 «La memoria, los sentidos y el entendimiento están todos ellos, pues, fundados en la imaginación, o vivacidad de nuestras ideas») (en el sentir vivaz de nuestras ideas, diríamos) (Treatise, L. I, P. IV, sec. VII, p. 265 ; trad. cast., p. 417).

${ }^{78}$ Cfr. Treatise, L. III, P. III, sec. XVI, p. 179; trad. cast., p. 309.

79 Treatise, L. II, P. III, sec. III, p. 415, trad. cast., p. 617.

80 Treatise, L. I, P. IV, sec. VII, p. 265; trad. cast. 416.

81 Sobre la presencia de Hume en el pragmatismo clásico, puede consultarse mi trabajo «Operatividad, verdad y creencia. Razón pragmática para un mundo desencantado». En Salas, J y Martín, F. (eds.), La formulación del pragmatismo. Aproximaciones a William James. Biblioteca Nueva, Madrid, 2005.

82 Es decir, entre una razón que busca fundamentos últimos, que acaba autodestruyéndose, pues desemboca en el escepticismo (más tarde Nietzsche diría en el nihilismo), y las «ilusiones de la imaginación», siempre bajo sospecha de que sus altos vuelos extravíen, como extravían la costumbre y la creencia acrítica, en efecto. (Treatise, L. I, P. IV, sec. VII, p. 268; trad. cast., p. 420)

83 Debo esta reflexión a la generosidad de José Luis Pardo.

${ }^{84}$ Como fuente de placer, por el simple hecho de ser una pasión. Al final del Treatise señala Hume que siente perderse un placer si no se dedicase a la filosofía. Igualmente es la satisfacción de este placer el origen de su filosofía (Treatise, L. I, P. IV, sec. VII, p. 271). También en Diálogos, p. 34 recalca que «se siente atraído por un cierto placer y satisfacción que él encuentra en conducirse de ese modo».

85 «Of the Dignity of Human Nature», The Philosophical Works, T.H. Green \& T.H: Grose, Aalen (Darmstadt), Scientia Verlag, 1964, vol. 3, p. 152; trad. cast. «De la dignidad o miseria de la Naturaleza Humana» en Disertación sobre las pasiones y otros ensayos morales. ed. de José Luis Tasset, Barcelona, Anthropos, 1990, p. 161.

86 Cfr. Enquiry, sec. I

87 Cfr. Historia natural de la religión, XV.

${ }^{88}$ Cfr. Diálogos, p. 25. 